\title{
The use of sonographic guidance in caudal epidural steroid injections
}

\author{
${ }^{1}$ Department of Surgery, Anesthesia and Intensive Care Section, G.B. Morgagni-Pierantoni Hospital, Forlì, \\ ${ }^{2}$ Department of Emergency, Anesthesia and Intensive Care Section, M. Bufalini Hospital, Cesena, Italy, \\ ${ }^{3}$ Medical Diagnostic Department Kingsbridge Private Hospital, Belfast, Northern Ireland \\ Emanuele Piraccini ${ }^{1,2}$, Giovanni Musetti ${ }^{2}$, Helen Byrne ${ }^{3}$, and Stefano Maitan ${ }^{1}$
}

\section{LETTERS TO EDITOR}

A Caudal approach to the epidural space through the sacral hiatus (caudal epidural injection, CEI) carries a lower risk of thecal sac puncture so is often preferred to a translaminar approach in those patients who have already undergone spinal surgery when epidural steroid injections are needed [1].

For many years, CEI has been performed using anatomic landmarks with relatively high risks of complications such as dural punctures, vascular and nerves root puncture, and intraosseous injection $[2,3]$.

Actually CEI is usually performed under fluoroscopic guidance using an injection of contrast media, however the radiation exposure can be a major issue as the ionizing radiation can generate excessive free radicals and cause cellular damage that increase with the energy of the radiation wave and the exposure time [1,2]. The radiation time should also be kept as low as possible so that the clinician performing the exam and other staff present in the room do not receive a greater radiation dose than is necessary, especially if these procedures are being performed regularly.

We show that sonographic guidance in conjunction with fluoroscopy can facilitate this. The use of sonographic guidance to facilitate CEI in adult patients has already been described [4], and the aim of our study was to evaluate the role of sonography in performing caudal steroid injections in patients who had previously undergone low back surgery, considering that the use of fluoroscopy is always needed to check the contrast media spread at the required target.

For each patient, we recorded the radiation exposure time and the numerical rating scale (NRS) score of the pain perceived during the procedure by the patient. The access to the sacral hiatus was obtained under fluoroscopic guidance (group F) or with sonographic guidance (group US).

CEI with an 18G Tuohy needle was performed with the patients in the prone position. Sonographic guidance began with the linear transducer in the short axis to identify the sacral cornua and sacrococcygeal ligament, and then by rotating the transducer by 90 degrees with the long axis to the sacrum, visualizing the sacral canal. The needle was inserted from caudal to cephalad direction into the sacral epidural space with an in-plane technique (Fig. 1). An epidural catheter was placed and contrast media was injected. Then an anteroposterior fluoroscopic image was obtained to confirm the correct spread (Fig. 2). The catheter was

Received March 6, 2018. Revised March 22, 2018. Accepted March 23, 2018.

Correspondence to: Emanuele Piraccini

Department of Surgery, Anesthesia and Intensive Care Section, G.B. Morgagni-Pierantoni Hospital, viale Forlanini 34, 47100 Forli, Italy Tel: +00390543735130, Fax: +00390543738635,E-mail: drpiraccini@gmail.com

(a) This is an open-access article distributed under the terms of the Creative Commons Attribution Non-Commercial License (http:// creativecommons.org/licenses/by-nc/4.0/), which permits unrestricted non-commercial use, distribution, and reproduction in any medium, provided the original work is properly cited.

Copyright (c) The Korean Pain Society, 2018 

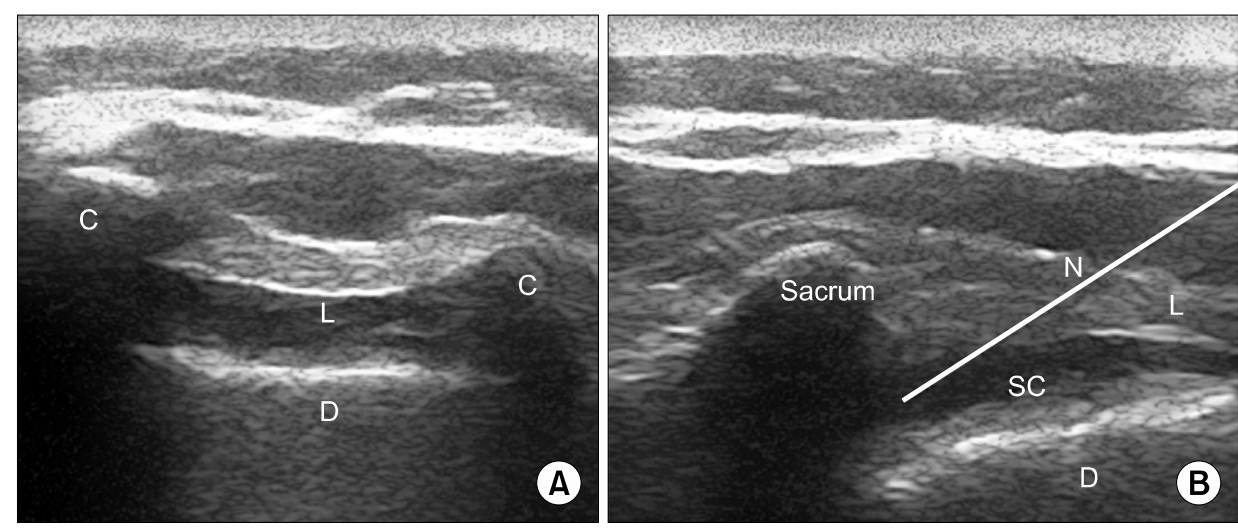

Fig. 1. (A) The picture shows the sacral cornua $\mathrm{C}$ as two hyperechoic reversed U-shaped structures. The hyperechoic bands in the center of the image are the sacrococcygeal ligament $L$ and below the dorsal surface of the sacrum D. (B) The picture shows the long axis to the sacrum visualizing sacrum and sacral canal with the needle trajectory $\mathrm{N}$.

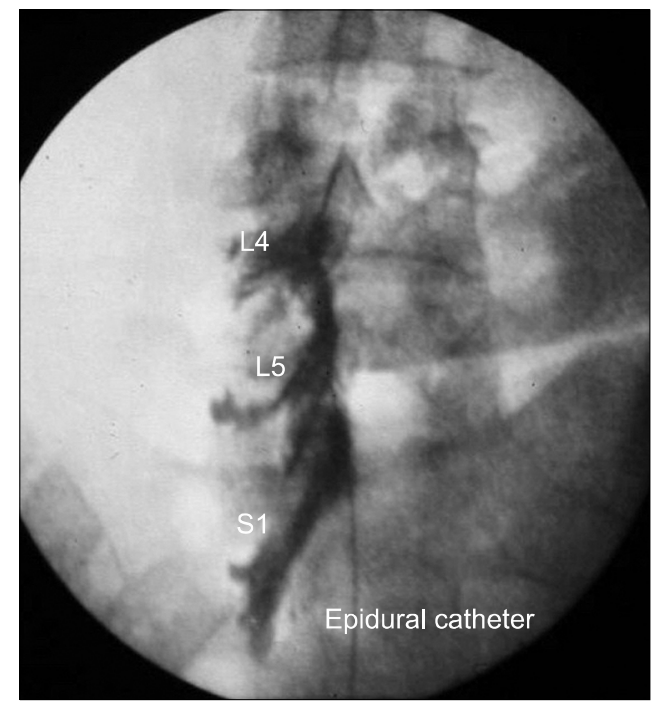

Fig. 2. Anteroposterior fluoroscopic image of a caudal epidural steroid injection through the epidural catheter with contrast medium. The contrast medium spreads along the left $L 4, L 5$ and $S 1$ nerve roots.

repositioned if needed to reach the required target.

Twenty patients were included in each group. The exposure time was $10.40 \pm 4.13$ and $1.50 \pm 0.76$ seconds $(P<0.001,95 \% \mathrm{CI}=6.93-10.87)$ while NRS score was $3.6 \pm 1.2$ and $2.0 \pm 0.9(P<0.001,95 \% \mathrm{CI}=0.83-2.47)$ for the $\mathrm{F}$ and US group respectively. Data were compared between the 2 groups with a paired student's t test and differences were statistically significant.

The sonographic guidance in this setting is important to locate the sacrococcygeal ligament and the sacral hiatus, so it is possible to have a real-time needle visualization while performing the procedure [4]. This could prevent potential complications such as vascular or nerve punctures, as these structures can be seen with ultrasound $[4,5]$. Sonography assistance was useful to reduce the exposure time during the whole procedure. The use of sonographic guidance to place the Tuohy needle in the sacral hiatus in CEI reduced the exposure time and the procedure was more tolerable and less painful for the patient when compared to CEI performed using fluoroscopic guidance only. Thus we recommend including it in normal clinical practice.

\section{CONFLICT OF INTEREST}

None of the authors has any conflict of interest.

\section{REFERENCES}

1. Manchikanti L, Singh V, Cash KA, Pampati V, Datta S. Management of pain of post lumbar surgery syndrome: one-year results of a randomized, double-blind, active controlled trial of fluoroscopic caudal epidural injections. Pain Physician 2010; 13: 509-21.

2. Akkaya T, Ozkan D, Kertmen H, Sekerci Z. Caudal epidural steroid injections in postlaminectomy patients: comparison of ultrasonography and fluoroscopy. Turk Neurosurg 2017; 27 : $420-5$.

3. Soneji N, Peng PW. Ultrasound-guided pain interventions a review of techniques for peripheral nerves. Korean J Pain 2013; 26: 111-24.

4. Klocke R, Jenkinson T, Glew D. Sonographically guided caudal epidural steroid injections. J Ultrasound Med 2003; 22: 1229-32.

5. Blanchais A, Le Goff B, Guillot P, Berthelot JM, Glemarec J, Maugars Y. Feasibility and safety of ultrasound-guided caudal epidural glucocorticoid injections. Joint Bone Spine 2010; 77: 440-4. 